Draft for Montreal Conference, 10-12 May 01

\title{
Akrasia, Collective and Individual
}

Philip Pettit

Perhaps the most famous analogy in the history of philosophical argument is that which Plato draws in the Republic between the constitution of the city and the constitution of the soul. The analogy is justly famous, for it sheds light on many aspects of mentality and personhood. In particular, as I shall try to show here, the analogy - or at least something close to the analogy — sheds light on the nature of akrasia or lack of self-control.

How to characterise akrasia? Without going into an analysis of our ordinary conceptions of the phenomena associated with this term, I shall assume that an agent is akratic when the following conditions are fulfilled. The agent holds by intentional states in the light of which a certain response presents itself as required; the states involved may be beliefs or desires, judgments or intentions, or whatever. The agent functions under conditions that are intuitively favourable, and within limits that are intuitively feasible, for acting as required; there is nothing abnormal about how things transpire within their constitution or circumstances - no malfunction, for example, or perturbation. But nevertheless the agent fails to act in the required manner.

This is a broad conception of akrasia and may not coincide in extension with received notions like that of weakness of will. Moreover, the conception described is going to vary in extension with any variation of extension in the related conception of normal conditions (Pettit 1999): for the record, I think that conditions of functioning will be abnormal so far as a person is affected by blind spots, idees fixes or fallacious habits of reasoning, or by affective pathologies or ineradicable compulsions, or is subject to mesmerising external forces of intimidation or temptation. But though the conception of akrasia is tied up in this way with the theory of normal conditions, and is not necessarily designed to track any received notions, still the phenomenon it purports to track assuming that there is indeed a phenomenon that answers to the conception - is bound to be of the greatest interest. 
I look here at what is necessary for a group to constitute an agent that can display akrasia in this sense, and at what steps such a group might take to establish self-control. I do so, not just because the topic has some interest in itself, but - the Platonic message - because the discussion suggests some lessons about how we should think of akrasia in the individual as well as in the collective case. Under the image that the lessons support, akrasia is a sort of constitutional disorder: a failure to achieve a unity projected in the avowal of agency. This image fits well with the constitutional model of the soul that Christine Korsgaard (1999) finds in Plato's analogy and her explication of the analogy offers a precedent - and indeed a prompt — for the line taken here.

The paper is in three sections. In the first I look at three sorts of groups that are incapable, so I argue, of akrasia; these I describe respectively as mere collections of individuals, mere aggregations, and ordered aggregations. In the second section I introduce a further sort of group, which I describe as an integration of individuals, and I argue that this is capable of akratic behaviour. And then in the final section I draw out some lessons of the discussion that bear on individual as well as collective akrasia.

\section{Groups incapable of akrasia}

A group or collectivity will constitute an agent just so far as it is the bearer of intentional properties: just so far as it forms attitudes like beliefs and desires, or judgments and intentions, and acts on their basis. There are a number of different accounts, each progressively richer than the preceding, of what is required for a group to be an agent in this sense. I shall argue that only a group which satisfies the richest account is capable of akrasia.

Collections of individuals

The least demanding account of what is required for a group to be an agent only ascribes agency in a very strained sense and need not detain us long. It is the sort of account suggested by Anthony Quinton $(1975,17)$ when he says:

To ascribe mental predicates to a group is always an indirect way of ascribing such predicates to its members. With such mental states as beliefs and attitudes, the ascriptions are of what I have called a summative kind. To say 
that the industrial working class is determined to resist anti-trade union laws is to say that all or most industrial workers are so minded.

According to this account, any number of individuals, no matter how arbitrarily related to one another, will be a bearer of intentional properties and will constitute an agent - albeit something less than an agent proper - just so far as the individuals in the group are the bearers of such properties. There is nothing to a group's being minded - being the bearer of mental properties and to its revealing that mind in action than is already assured by the fact that it is a collection or set of individually minded agents.

This account is so generous that it amounts, as indeed Quinton intends, to an eliminativism about group agents. In the easy, summative sense in which a collection may hold a certain attitude - say, the belief that $\mathrm{p}$ - any subset is just as likely to hold an attitude, even a conflicting attitude, and so is any larger set of which the collection is a subset. The account makes it so easy for collectivities to hold attitudes that it represents them as agents only in a makebelieve sense: 'only by figment, and for the sake of brevity of discussion' (Austin $1869,364)$. No such fictive agents could display anything remotely like akrasia. Far from holding by attitudes which they might fail to live up to in action, they hold by no attitudes whatsoever (Pettit 2000).

Aggregations of individuals

The debunking account of group agency that Quinton represents has been roundly rejected in the recent literature and has served as a stimulus to the development of a family of much more demanding analyses. These analyses agree that a group cannot have intentional attitudes in a serious, literal sense, just in virtue of most of its members having corresonding individual attitudes. The members must do something, as we might put it, in order to bring group attitudes into existence. They must form intentions about what is to transpire, they must reveal those intentions to one another, and they must adopt measures that give effect to relevant intentions: measures such as those involved in accepting a certain formula as a matter of joint belief or endorsing a certain authority as acting on behalf of the group. This style of analyis focusses on group 
intentions and group judgments, where judgments are beliefs associated, not just with a disposition to action, but with the acceptance of a formula. It suggests and I shall go along with the idea - that those are going to be the principal kinds of intentional state that collectives exemplify.

The approach generally followed in this literature is to take a grouping of two or perhaps three agents and to try and identify the conditions under which we would ascribe a collective intention or judgment or action to them (Gilbert 1989; Meijers 1994; Searle 1995; Tuomela 1995; Bratman 1999). The analyses all draw in some way on work in game theory and related disciplines, in particular on the idea that people in interaction will form beliefs about one another's dispositions, beliefs about one another's beliefs about such dispositions, beliefs about one another's beliefs about such beliefs, and so on.

The analyses generally agree that in order for joint intention to appear, for example, people must share in a mutual belief of this sort that bears on what each believes about the dispositions and beliefs of others, and on how each is ready to act in the event of others acting in a complementary way. Thus Michael Bratman (1999) argues that you and I will have a shared intention to do something just in case a) you intend that we do it and I intend that we do it; $b$ ) we each intend that we do it because a) holds; and c) those clauses are matters of which we are each aware, each aware that we are each aware, and so on in a hierarchy of mutual belief. The hierarchy will mean that each believes the matter in question - say, that p; each believes that each believes that $p$; each believes that each believes that each believes that p; and so on. And so on, most plausibly, in this mode: while not everyone may believe the required condition at each higher level, at least no one will disbelieve it at any such level (Lewis 1969). ${ }^{1}$

I am happy to assume that a common-belief analyis of some kind will give us a plausible story as to what is involved in a group's forming a judgment or intention, or performing an action. Common beliefs about the group's judgments and intentions will materialise fairly spontaneusly among people in face-to-face groups of two or three. And they will materialise in groups with larger memberships on the basis of common beliefs as to the procedures to be followed in identifying the judgments and intentions of the group. Those 
procedures will typically involve voting among members - majoritarian voting in most plausible instances - or voting among those whom members elect as authorities. The votes required may be active or virtual. Someone will cast a virtual vote in favour of an arrangement or initiative to the extent that they could contest it - with whatever chance of success - but choose not to do so. To vote for something in the active sense is to say 'Yea'; to vote in the virtual is to be in a position to say ' $\mathrm{Nay}^{\prime}$ and to refrain from exercising that option.

We had no hesitation in saying that a group agent that is merely a collection of individually minded agents cannot display anything approximating akrasia. But what now of the group agent that aggregates its views from the views of individual members, whether on the basis of some formal voting mechanism or in a more spontaneous manner. What of the sort of group that we can describe as an aggregation, as distinct form a mere collection, of individuals? Such an aggregated group will be minded on an indirect basis that allows the mind of the group — its pattern of judgments and intentions — to come apart from the minds of its individual members. So does that mean that it will be capable of akrasia? I argue not.

The group will aggregate its group attitudes from the attitudes of individual members, forming on every issue an attitude that reflects the inputs of those members. In the typical, large-scale case it will tend to do this by relying on some explicit or implicit voting procedure. But the trouble with a group agent that operates solely by such aggregative moves is that it may not have the sort of unity or integrity that we require in an agent proper, and in particular in the sort of agent that is capable of akrasia.

By a line of argument that has been widely endorsed in recent philosophical thought, a system will count as an intentional subject only if it preserves intentional attitudes over time and forms, unforms and acts on those attitudes - at least within intuitively feasible limits and under intuitively favourable conditions - in a rationally permissible manner: only if it displays a certain rational unity (Dennett 1987; Pettit 1993. Ch.1). If the system believes that $\mathrm{p}$ and comes across evidence that not $\mathrm{p}$, it must tend to unform that belief. If the system believes that $\mathrm{p}$ and learns that if $\mathrm{p}$ then $\mathrm{q}$, it must come to form the belief 
that $q$ or to unform one of the other beliefs. If the system desires that $p$, believes that by $X$-ing it can bring it about that $p$, and believes that other things are equal, then it must tend to $X$. Let the system fail in such ways - in particular, let it fail in ways that cannot be explained by departures from favourable conditions or by breaches of feasible limits - and we will have to conclude that the states we took to constitute intentional attitudes do not actually constitute attitudes after all; they do not function in the manner required.

Even if we introduce the sort of complexity postulated in aggregative stories about collective agents, that will not guarantee that those subjects have the rational unity associated with intentionality. Those stories are all consistent with the collectivity's acting by conventions that allow rational disunity. The convention established in the mutual awareness of members may ordain, for example, that the collectivity shall be deemed to judge or intend whatever a majority of members vote for its judging or intending in a given case. And it is demonstrable that if such a convention obtains - if the attitudes of the collectivity are required to be continuous in that majoritarian way with the current votes of members - then the collectivity may be guilty of grievous irrationality. The convention will enable the group to form putative judgments and intentions one by one, but it will allow the formation of judgments and intentions that fail to cohere with one another as a whole. It will allow the group to sustain such an irrational jumble of would-be judgments and intentions that we cannot think of it as an intentional agent proper and we cannot think of the states formed as judgments and intentions in any proper sense of those terms.

How to demonstrate the threat of such a failure of rational unity? I have written elsewhere on the problem involved - the discursive dilemma, I call it and I shall summarise the line of argument briefly here (Pettit 2000; List and Pettit 2001; Pettit 2001). The problem derives from an issue first raised in jurisprudence (Kornhauser and Sager 1986; Kornhauser 1992; Kornhauser 1992; Kornhauser and Sager 1993. See too Chapman 1998; Brennan 1999). In essence, it comes to this. If we take a set of rationally connected issues and then ask a group of people to determine its view as a group on each of those issues, a majoritarian pattern of voting may lead the group to endorse inconsistent positions. It may do 
this, in particular, without any members of the group being individually inconsistent in their votes.

Suppose for example that a group of three people, A, B and C, has to determine its views on each of three propositions, ' $\mathrm{p}$ ', 'if $\mathrm{p}$ then $\mathrm{q}$ ' and ' $\mathrm{q}$ ', and that the procedure they follow is to assent to a proposition in the event of a majority supporting it, and to dissent otherwise. It is entirely possible that the members of the group will cast their votes on the pattern involved in Matrix I, for each individual expresses a consistent set of views in the votes that he or she casts according to that matrix. But if they do cast their votes on that pattern, then a majority will support ' $\mathrm{p}$ ', a majority support 'if $\mathrm{p}$ then $\mathrm{q}$ ' and yet a majority reject ' $q$ '. And in that case the group as a whole will be committed to an inconsistent set of judgments.

$\begin{array}{lccc} & \mathrm{p} & \text { if } \mathrm{p} \text {, then } \mathrm{q} & \mathrm{q} \\ \text { A. } & \text { Yes } & \text { No } & \text { No } \\ \text { B. } & \text { No } & \text { Yes } & \text { No } \\ \text { C. } & \text { Yes } & \text { Yes } & \text { Yes } \\ & & \text { Matrix I } & \end{array}$

The problem that the discursive dilemma makes vivid is that it is possible for perfectly consistent and coherent individuals to give majority support to each of a set of inconsistent or incoherent judgments. The members comprising the different majorities may vary so that there is no individual who belongs to the majority on each issue and who is guilty as an individual of irrationality. In the scenario depicted in Matrix I, for example, there is a majority in favour of ' $\mathrm{p}$ ', a majority in favour of 'if $\mathrm{p}$, then $\mathrm{q}$ ' and a majority in favour of 'not q', but there is no individual who votes for each of the judgments in that inconsistent set. A votes against 'if $\mathrm{p}$, then $\mathrm{q}$ '; B against ' $\mathrm{p}$ '; and $\mathrm{C}$, in effect, against 'not $\mathrm{q}$ '.

The lesson should be clear. In order for a collectivity to count as an intentional agent in a literal sense - and therefore as an agent capable of akrasia - not only must there be a basis in the interactive disposition of members for ascribing judgments and intentions and actions to the collective; that is the point on which the mutual-awareness literature rightly insists. There must also be a basis for thinking of the collectivity as a subject that is rationally unified in such a 
way that, within feasible limits and under favourable conditions, we can expect it to live up to the constraints of rationality; we can expect it to enter and exit putative states of belief and desire, judgment and intention, in a way that makes rational sense and we can expect it to perform in action as those states require. But the existence of discursive dilemmas means that there is no reason to expect a mere aggregation of individuals to display rational unity in the attitudes it aggregatively constructs, even in intuitively the most normal of circumstances: even, for example, when everyone in the group is rational, well-informed and free to vote as the wish. Thus there is no reason to treat the mere aggregation of individuals as an agent proper; there is no reason to think that it will have a single, unified vision by which to orientate in the world.

This observation is enough on its own to ensure that the mere aggregation is incapable of akrasia; there can be no akrasia without agency proper. But the point in any case is palpable. Just as the group in Matrix I asserts that $\mathrm{p}$ and that if $\mathrm{p}$ then $\mathrm{q}$ but denies that $\mathrm{q}$, so a group might be led by aggregation - led even in the most normal of circumstances - to endorse propositions that make a certain action rational and yet to reject that action. Would we be inclined to postulate akrasia in such a case? Of course not. If there were no reason to expect the group to act according to the other propositions endorsed, then there would be no need to resort to a hypothesis of akrasia in order to explain its failure to act in that way.

The discussion so far supports two negative results: first, that a mere collection of individual agents cannot display group akrasia and, second, that a mere aggregation of such agents cannot do so either. But there is a third negative result that we can also derive from consideration of these cases and I turn now to this.

Ordered aggregations of individuals

Suppose that an aggregation of individuals operates by voting on separate issues as they come up one by one. And now imagine that for some reason maybe as a result of how the members are designed at unconscious levels of performance - the voting gives rise to irrational results only under conditions 
that we can independently discount as abnormal conditions of functioning. The aggregation is rationally ordered, though only in a more or less mechanical manner. Could we regard such an ordered aggregation as an intentional agent? And, more particularly, could we regard it as an agent that is capable of akrasia?

The sort of group agent envisaged - and I do not say that it is a plausible entity - would resemble the simple intentional system that most of us take nonhuman animals like cats and dogs to be. Dogs appear to form attitudes of belief and desire, to act on the basis of those attitudes, and to update them appropriately so that under most conditions of functioning we think of them as satisfying constraints of consistency and the like. Yet they do not do this through ever becoming aware of irrationalities as such and adjusting so as to avoid them. They are designed so that under normal conditions, as we intuitively think of them, such irrationalities just happen not to emerge. The ordered aggregation envisaged under our current hypothesis would display a similar, blind disposition to avoid irrationality, at least under most circumstances, and it would make a similar claim to be regarded as an intentional agent.

I am happy to think of dogs and cats as intentional agents. They act in a manner that is well explained by the presence of intentional attitudes and they are disposed, however blindly, to display rational unity (Pettit 1993; McGeer and Pettit 2001). For the same reason, then, I am happy to think that the ordered aggregation envisaged in our thought experiment might count as an intentional agent too. But would it count as an agent capable of akrasia? As in the case of the collection and the regular aggregation, I argue not.

Suppose that the ordered aggregation makes certain putative judgments, or forms certain putative intentions, apparently recognising in light of those states that a certain response is required of it. And imagine now, as we might expect of an akratic agent, that it fails to display that response. Would we be entitled in these circumstances to ascribe akrasia to it? By the account of akrasia sketched at the beginning of this essay, we would be entitled to take the aggregation as akratic if it were indeed an intentional agent and if conditions of functioning were normal. But if the ordered aggregation failed to display rational unity under normal conditions, then that would mean that we had no reason to 
take it to be an intentional agent. Or at least it would mean that we had no reason to take it to be an intentional agent with judgments and intentions such that it failed to live up to them. We might try to save the imputation of agency by revising the judgments and intentions ascribed but we would never be in a position to think both that it was a proper agent and that it manifested akrasia. The condition necessary for postulating akrasia - that relative to the intentional attitudes ascribed it falls short of rational unity under normal conditions - is a condition that would be sufficient for denying intentional agency or for revising the ascription of intentional attitudes so as to restore the semblance of unity.

The problem with the ordered aggregation is that it counts as an intentional agent only so far as it reveals intentional attitudes in a rationally unified pattern of operation. There are states it enters and exits such that the ways they are formed and unformed - say, by on the basis of voting - and the ways they operate in relation to one another, and ultimately in relation to behaviour, reveal them to be intentional attitudes. Let the ordered aggregation fail on the operational side, therefore - let it fail to display rational unity under conditions that cannot be discounted as abnormal for functioning — and its title to being an intentional agent must falter. There will be no room for entertaining the hypothesis that it is an intentional agent but one that is suffering akrasia.

This third result should be no surprise, given that the ordered collectivity is an analogue of the non-human animal that achieves rational unity in a blind or mechanical way. For the argument just used will apply to non-human animals as well. Anything that might be taken as evidence of akrasia in such an animal will tend to undermine our confidence that it is an intentional system. Or it will lead us to revise our account of that creature's intentional attitudes, so that it no longer looks akratic. It is no surprise, therefore, that by our ordinary lights dogs and cats and the like do not display anything like akratic behaviour.

\section{A group capable of akrasia}

We have seen that collective akrasia is not going to be realisable in a mere collection of individuals, in a mere aggregation of individuals or even in an ordered aggregation of individuals. But these three negative results point us 
towards a positive claim and I try to describe and defend this claim in the present section.

In order for a collection of agents to be capable of counting as an intentional agent in its own right, and therefore as an agent capable of akrasia, it is necessary for it to be able to form states that are fit for the role of intentional attitudes: say, the role of judgments and intentions. Call this the aggregative requirement of collective agency. But in order for those states actually to play the role of intentional attitudes it is equally necessary that the collection be able to unify them rationally with one another and with the behaviours that can be ascribed to the group. And if the collection is to be the sort of agent that can display akrasia, it is necessary that it be able to unify them rationally in something more than the mechanical manner of the ordered aggregation. Call this the integrative requirement of collective agency.

With the aggregative and integrative requirements in mind, we can describe the profile of a group that transcends the collection and the aggregation — the bare aggregation or the ordered aggregation — of individuals. This will constitute what we might describe as an integration of individuals. It will be an aggregated collection that takes steps to promote the achievement, as such, of rational unity or integrity.

It is relatively easy to see how such a group might emerge. Let a collection of people establish or grow into a common purpose or purposes, on the basis of various levels of common belief. Let it face a variety of issues, some at the same time, some at different times, that it needs to resolve in order to pursue its purposes. Let it initially determine its view about each of those issues - taken separately - on the basis of some majoritarian form of voting, active or virtual. Let it baulk, however, in the event of the views thereby espoused - whether at the same or at different times - proving not to cohere with one another, or not to cohere with the actions that it is deemed to take: let it be sensitive as such to the requirements of coherence, recognising that they are grounded in the requirements of agency. And, finally, let it take steps in such an event that guard against rational disunity; let it strive to endorse only views that can be integrated 
with one another into single rational vision of how things are and of how it is desirable that they should be. ${ }^{2}$

The integration of individuals established on the basis of such a mode of functioning would have an irresistible claim to being an intentional agent in its own right. It would embrace a rationally unified vision of things and it would act rationally on the basis of that vision. Moreover, it would show itself to be aware of the constraints that must be satisfied by a rational agent and it would be disposed to act so as to try to satisfy those constraints. It is hard to see what further credentials could be required in order to establish agency. True, the group envisaged will have no autonomous means of perception, no emotions in its own right, and no spontaneous inferential or other dispositions; it will exist and operate only by courtesy of individual contributions and only under mechanical procedures of aggregation and correction. But the group envisaged will have a robustly unified vision of the world and will generally act as that vision requires. However bloodless and robotic it may be, there is no good reason to deny that it has the standing of an agent. So at any rate I shall assume here.

The elements required for the emergence of an integration of agents are all readily available in day-to-day life. The richest requirement is that the members of the group have to be aware as such of the constraints to be satisfied by a rational agent, so that they can adjust appropriately if they find that the constraints are breached. But this is not problematic. We have already assumed that in aggregating their views into collective beliefs the members rely on getting the group to accept relevant formulae. If people understand a formula, say ' $\mathrm{p}$ ', then they have to know, more or less fully, what sort of thing provides inductive evidence in its favour and what provides evidence against; which propositions are consistent with it and which inconsistent; which propositions entail it and which are entailed by it; and so on. But if they know this, then they know the constraints of rationality that a believer that $\mathrm{p}$, or of course someone who intends to make it the case that $\mathrm{p}$, will have to satisfy; what those constraints rule out are precisely responses that breach inductive coherence, deductive consistency and the like. 
Integrations of the kind described are perfectly familiar entities. Think of public bodies or business corporations or private associations or think of a few collaborators in some enterprise. Every such collection of people is going to have a more or less well-identified set of purposes to which its members have to subscribe. And every such collection is going to form judgments and intentions in the course of devising plans for the advancement of those purposes. The judgments and intentions are likely to be formed on the basis of explicit voting procedures, whether in the group as a whole or in one or another unit that it comprises. But the votes taken under such procedures will never be allowed to generate rational disunity. If they happen to propose an irrational set of judgments or intentions then the group will take steps to revise or moderate the votes taken. Any group that regularly failed to do this would find itself unable to act systematically in pursuit of its goals; it would find itself trying to orientate by an inconsistent map. And any group that failed to do this would be a laughing stock among its members and among the populace at large.

But would the integrated group of the kind envisaged be an agent capable of akrasia, or just an agent like the ordered aggregation that we would never have compelling reason to treat as akratic? That is the crucial question for our purposes. I now proceed to argue, in positive vein, that there is little or no difficulty in thinking that an integration of individuals might prove to be an akratic agent.

There are three observations I make in the course of marshalling the argument. The first is that there is no problem of the kind that arose with ordered aggregations in acknowledging that integrations may be akratic. The second is that we can see why integrated collectivities might be subject, even in conditions that count as perfectly normal, to akrasia; we can see a difficulty in which akrasia might be sourced. And the third is that we can see strategies whereby an integrated group might hope to get over that difficulty and to avoid akrasia. This last observation is important because we would be loathe to postulate lack of self-control in an agent that was incapable of making successful efforts to achieve self-control.

First observation 
The problem that would stop us from ascribing akrasia to the ordered collectivity is that the condition necessary for doing this - that the agent fails to achieve rational unity under normal conditions of functioning - would deprive us of reason to support the ascription of agency in the first place. This problem will be overcome only where the failure to achieve rational unity does not undermine the claim to agency in this way. The potentially akratic group must be able to prove itself capable of agency despite displaying the rational disunity associated with akrasia.

The integrated group characterised above will be able to meet this constraint. We can readily imagine such a group failing to behave in the way that the views it supports require, even under conditions that we have no independent reason to regard as abnormal. And we can imagine this happening in circumstances where we would have no reason to doubt its status as an intentional agent. For the integrated group is capable, under our characterisation, of recognising rational constraints as such. And so it is capable of recognising, admitting and denouncing the failure involved, seeing it as a sort of failure that it should avoid.

If the group does this, and if we accept its sincerity, then there is going to be no problem in taking it to have intentional attitudes that it failed, despite conditions of functioning being normal, to act on. The fact that the group reaffirms the intentional states that it failed to live up to, acknowledging that failure as a failure, will make for a big contrast with the situation that might arise in the case of the ordered aggregation. It will give us a powerful reason to countenance the group as an intentional agent, dismissing the counter-evidence that its behaviour constitutes. And if we do continue to take it as an intentional agent, without revising our ascription of intentional attitudes, then we will have to ascribe akrasia to it.

The failure involved in akrasia means that the group does not satisfy the requirement of rational unity in the ordinary way that we would expect of an intentional agent. But it is worth noting that the acknowledgement of failure will help to put right this shortfall from unity. When an integrated group admits such failure, then it can be seen as disowning the akratic action, denying it the status 
of a behaviour that reflects its intentional states: its presumpitively unified way of seeing the world. It can be seen as laying claim to rational unity of a secondbest sort: a unity that can exist in spite of the disunity displayed in actual behaviour.

Second observation

The second observation I want to make is that the sort of failure associated with akrasia is perfectly intelligible in the case of the integrated group. There is a compelling reason why we might expect a group of the sort envisaged to find it difficult to get its act together and to manifest in action a unified understanding of what there is and what there ought to be. There is a compelling reason to expect such difficulty - and the possibility of failure - even when the group is functioning in intuitively normal conditions. This has to do with the fact that any integrated group is going to be plagued by discursive dilemmas.

Consider a simple group that operates by taking a majority vote on every issue that it confronts in the course of pursuing its purposes. The group may be the editorial committee of a journal, the workforce in some joint enterprise, a body that is commissioned to discharge a certain public duty, or whatever. Suppose that the group operates under intuitively normal circumstances: nothing stops members from debating fully and rationally the position that they ought to adopt on each issue, none of them is prey to any sort of irrationality in the votes that they cast, the voting procedures followed do not give rise to any particular difficulty, and so on. It is entirely possible, nonetheless, that the group will confront discursive dilemmas, as this was possible with aggregations of people. And it is entirely possible that despite the fact of operating in normal conditions, and despite the fact of having and trying to exercise the selfregulative resources needed to promote collective rationality - these are the resources unavailable to the aggregation - still, it will fail to act as its official and continuing view requires it to act. It is entirely possible, in other words, that it will display akrasia.

The point is best established with reference to an example. Take a noncommercial academic journal with an editorial committee of three members that 
resolves all the issues it faces by majority vote and that is not subject to intuitively abnormal conditions of functioning. Suppose that the committee votes in January for promising subscribers that there will be no price rise within five years. Suppose that it votes in mid-year that it will send papers to external reviewers and be bound by their decision as to whether or not to publish any individual piece. And suppose that in December it faces the issue as to whether it should be prepared in principle to publish papers that involve technical apparatus and are quite costly to produce. The earlier votes will argue against its being prepared to do this, since a rise in the number of technical papers submitted and endorsed by reviewers - endorsed, without any eye to overall production costs - might force it to renege on one or other of those commitments. But nonetheless, of course, a majority may support the acceptance of technical papers, without any individual being irrational. The members of the committee might vote as follow.

$\begin{array}{llll} & \text { Price freeze } & \text { External review } & \text { Technical papers } \\ \text { A. } & \text { Yes } & \text { No } & \text { Yes } \\ \text { B. } & \text { No } & \text { Yes } & \text { Yes } \\ \text { C. } & \text { Yes } & \text { Yes } & \text { No } \\ & & \underline{\text { Matrix II }} & \end{array}$

Discursive dilemmas of this kind present a group with a hard choice. Members have to choose between, on the one side, letting the group be fully responsive to individual views, as recorded in majority voting, and on the other, ensuring that the group is collectively rational. Sometimes it will be hard for the group to determine where the demand for collective rationality leads: whether they should revise one of the earlier votes in Matrix II, for example, or the vote they have just taken. But even if there is no difficulty of this kind - even if it is clear what collective rationality requires of the group - they may find it hard to live up to that requirement; they may find themselves prey to akrasia.

They will not find it hard to live up to the requirement, of course, if they are individually devoted to the group and are in no way tempted to defect from what the group requires of them. A group whose members were dedicated in this way would operate like a perfectly virtuous agent, always spontaneously 
supporting what the balance of available reasons requires of the group. But not all members need be so devoted to the group in which they figure; and when something less that full collective devotion is on offer, then it may prove very difficult for members to get their act together and ensure that the group lives up to the considerations that it endorses.

Suppose in the example just given that the group looks again at its votes in the first two columns and decides that they should stand, whether on their own merits or because it is now too late to change them. In other words, suppose that the members quickly resolve the question as to what collective rationality requires of the group: it requires them to limit the number of technical papers to be accepted. It is still possible in this event, and without conditions of functioning ceasing to be normal, that the group will find it hard to act on that determination: in effect, to act against the majority who support an open policy on technical papers.

That majority might remain individually and stubbornly inclined to support the acceptance of technical papers. And so we can imagine them turning their eyes from the group as a whole, and sticking to their votes when the issue is raised again. As we imagine this, we envisage the group taking an akratic line in the policy it is forced to announce in December. Without doubts arising about its status as an intentional agent - we might expect it to acknowledge and try to rectify the failure, if it gives rise to difficulty - we can imagine it falling away from the ideal of unified agency, due to its betrayal by members of the recalcitrant majority.

What might motivate the recalcitrant majority in the sort of case envisaged? They might be moved by a more or less selfish inclination or identification, being technically minded themselves; or they might be moved by a sense of fairness towards those who would be disadvantaged; or whatever. Personal virtue is as likely as personal vice to source recalcitrance towards a collectivity. Virtue in the individual members of a group may make for akrasia in the group as a whole. 
But could it really be rational for the recalcitrant members to stick to a deviant pattern of voting? I don't see why not. They would satisfy their private motives, selfish or virtuous, by doing so. And they might individually expect to get away with such voting, being outvoted by others; they might expect to be able to free-ride. Or they might hope that even if a majority remains recalcitrant, this will not cause problems: there will not be a deluge in the number of technical papers submitted and accepted, and the committee can get away with holding by all of the three commitments involved.

What will happen if the recalcitrant majority are wrong in these hopes, and the group does not get away with such recalcitrance in its ranks? On pain of no longer having a claim to be an agent proper - or at least an agent proper in the relevant domain of activity - the group will have to take measures to bring the recalcitrant majority into line. For it will have to admit the failure and, in token of the admission, go to a reversal of policy. Unless it does this it cannot be represented - and it cannot represent itself - as an agent that acts out of a rationally unified view of the world. It can be seen only as an aggregate of different agents, not as an agent unified within itself: only as many, not as one.

Third observation

The final observation I want to make in support of my claim that integrated groups can display akrasia is that there are strategies available to any such group whereby it might seek to guard against this sort of failure. One way in which a group might be protected against akrasia, of course, would be through its members being individually so devoted to the collectivity that it inevitably behaves in the fashion of a virtuous agent. But short of such a radical alternative to akrasia, there are a number of means whereby a group might try to ensure that it achieves continence: that is, a form of self-control that does not require virtuous devotion (Pettit and Smith 1993).

The strategies I have in mind often serve two purposes: first, to show the group a salient way out of a discursive dilemma, by identifying a course of action whereby coherence can be achieved and, second, to guard against the unwillingness of some members to go along with that course of action. The first 
purpose is associated with self-direction, the second with self-control. Here we are only concerned with the strategies as means of achieving the second, selfcontrolling effect (see List and Pettit 2000).

The first and most obvious strategy for promoting self-control in a collectivity would be for the group to ensure that the costs of failing to achieve such self-control are significant. The members might precommit themselves to being collectively rational, for example, exposing themselves to a cost that all will have to bear in the event of failing to achieve such rationality. Or the members might lay down procedures under which those who remain recalcitrant in the attempt to achieve collective rationality will be expelled or punished in some way.

A second sort of strategy for achieving collective continence would have the group seek, not to raise the costs of failing to achieve self-control, but to restrict the opportunities for such failure. Thus the group might restrict the range of matters in respect of which it acts, recognising that troubles loom outside the boundary thereby imposed. This strategy may only be of limited use, of course, since the group may not be able to impose an effective boundary without compromising its ability to advance its purposes. Or, alternatively, the group might take steps to try and ensure that differences of the sort that give rise to discursive dilemmas do not emerge. The group might seek, by whatever means, to bring members of the group together in their views as to what the group should judge and on how it should act. The means adopted could involve an increase in deliberative discussion - though that could backfire by sharpening rather than moderating differences (Sunstein 2000) - or a resort to less savoury ways of shaping and homogenising people's opinions.

A third sort of strategy whereby a group might achieve self-control - and indeed self-direction — is probably more promising. The members of the group might follow a procedure whereby the decision on problematic issues is taken out of their individual hands. They might arrange to have such matters decided by more or less automatic procedures. This sort of self-denying ordinance comes in two particularly salient versions. 
Under the first version of the strategy the group would agree in advance that should different majorities support incoherent positions on related issues, then the positions adopted on certain sorts of issues should dictate, independently of majority vote, the position that the group should adopt on other issues. Thus the group might decide that in the event of majorities having endorsed in the past positions that dictate a position on an issue that arises later, the earlier votes should rationally dictate the group position on that later issue. Or a group might decide that the positions adopted on more general, principled issues should rationally dictate the position to be adopted on matters of greater detail. Or whatever.

Under the second version of this strategy, the group would agree that, in the event of recalcitrance causing a problem - or indeed more generally - the group position should be determined by some designated officer, or perhaps by a small committee that is not so likely to be affected by discursive dilemmas. This strategy would enable the group to transcend the difficulty raised by such dilemmas in a smooth and unproblematic manner, though it would compromise

the participatory character of the collective. As the first version privileges certain considerations in the formation of group views, this second version would privilege certain members.

These remarks should be sufficient to indicate that not only are integrated collectivities likely to be plagued by a malaise resembling akrasia. The malaise in question looks to be well deserving of the title of 'akrasia', so far as those groups are also likely to have access to strategies of self-control: strategies whereby the group can keep itself collectively rational, even though its members may not be whole-heartedly devoted to it.

\section{The lessons}

The fact that akrasia in collectives takes the form described in the last section tells us something about akrasia as such and in this final section I mention some lessons that we can draw from the discussion. I concentrate on three lessons in particular: first, that akrasia is not mechanical in character; second, that it is not essentially a hierarchical phenomenon in which lower-level 
elements revolt against a higher; and third, that it is not exclusively actioncentred in its manifestations: it can affect intentional states as well. In defending these lessons, I give support to something close to what Christine Korsgaard (1999) describes as a constitutional model of the role that reason plays in the person, though I do not defend the distinctively Kantian views with which she is associated.

Akrasia is not mechanical in character

The first lesson, according to which akrasia is not mechanical in character, derives from the discussion in the first section, where we saw that akrasia has no place in the mere collection, the mere aggregation or the ordered aggregation of individuals. The ordered aggregation of individuals represents a collective agent that operates in a more or less mechanical way, paralleling the mode of operation most of us ascribe to non-human animals like dogs and cats. It relies on voting and other mechanisms that generate candidate states for the role of judgments and intentions. And the psychology and organisation of its members ensures, without anyone necessarily being aware of the fact, that those states will actually implement that role, at least under intuitively favourable circumstances and within intuitively feasible limits. They ensure that the ordered aggregation will achieve and maintain rational unity in the way it forms and unforms such states and in the way the states lead to action.

We argued earlier that the ordered aggregation cannot be indicted with akrasia because any failure to achieve rational unity would put its status as an agent in question, so that there would be no room for thinking that it is an agent but one that is akratic. We supported that observation by pointing out that something very similar is going to be true of the non-human animal. Let such an animal behave in a way that makes no sense in the light of the intentional states ascribed to it, and let conditions be intuitively normal. We will conclude in such a case either that it is not an agent proper or that our initial ascription of intentional states was mistaken. We will not have any good reason for regarding it as an akratic agent. 
The lesson drawn in our discussion of collectives was that if a group agent is to be capable of akrasia then it must be an agent that can be aware as such of the constraints of rationality and that it must be able to regulate itself in the light of those constraints. Only an agent of that kind could fail to achieve rational unity in action, even in intuitively normal conditions, and yet count as an intentional agent proper. Only an agent of that kind would be able to establish its status as a rationally unified subject through recognising and admitting the failure, representing the action in question as something that it does not endorse or own and as something, therefore, in which it was not really present as an agent.

The point made here would seem to apply more generally, as indeed we saw in the case of non-human animals. What it establishes is that akrasia presupposes a sort of agent that is not just brutely disposed to achieve a certain rational unity in action but that has the capacity to work intentionally at the achievement of such unity. The agent must be able to recognise the constraints that have to be satisfied by any system that holds by certain profiles of belief and desire and the like. And it must be able to identify the requirements of those constraints in its own case and, in principle, to regulate its performance so as to meet those requirements (Pettit 1993; McGeer and Pettit 2001).

This lesson, to put it a bit more sharply, is that the agent that is capable of akrasia has got to be something more than just a decision-theoretic system in which states of belief and desire mutate and materialise in action according to standards requirements of rationality (pace Jackson 1984; see Pettit and Smith 1993). It has got to be able to express such states in assertions about what is the case and about what would ideally be the case, so I surmise, recognising in virtue of that ability that this or that action is required of it: and recognising this, despite the occasional failure - even in intuitively normal conditions - to act in the required way. No failure in a decision-theoretic system would give us reason to ascribe akrasia if the subject in question did not have this sort of ability; it would only give us reason to posit a malfunction or to think again about our initial ascription of intentional states.

Akrasia is not necessarily a hierarchical phenomenon 
The second lesson that I derive from our discussion is that akrasia is not an essentially hierarchical phenomenon. Traditional discussions of akrasia suggest that it has a deeply hierarchical aspect, representing the failure of a higher self to subdue a lower self, or the failure of the superior faculty of reason to suppress the base passions. 'Every rational creature, 'tis said, is oblig'd to regulate his actions by reason; and if any other motive or principle challenge the direction of his conduct, he ought to oppose it, 'till it be entirely subdu'd, or at least brought to a conformity with that superior principle' (Hume 1978, 413).

The striking thing about the akrasia that we identified in collectives, however, is that it does not have a hierarchical aspect at all. The elements that are in conflict when akrasia strikes are coordinate factors, not factors that are arranged in any order of power or authority. They are simply the different individuals involved, as in the example of the editorial committee that we discussed. Each of these has his or her own view as to what the group should judge and do and each is generally disposed to play his or her part in the integration of the group as an agent proper. But even when the demands of integration are discerned among the members, and even when conditions of functioning are normal, each is subject to the possibility of a certain recalcitrance of motivation. When that recalcitrance surfaces on a wide front, the individuals fail to get their act together and the group fails to act as its commitments require. And that failure is precisely what constitutes akrasia.

If we agree that there is collective akrasia of this kind, then we must agree that akrasia is not necessarily hierarchical in character. But does the collective case suggest, more strongly, that akrasia in the individual may also take a nonhierarchical form? I think that it does, though I shall only sketch the possibility here, not provide a proper defence.

The individual who escapes akrasia, like the collective that does so, will prove thereby to be a creature of reason. But that this is so does not mean that reason is itself a faculty that has to impress its rule on more rebellious elements in the personality. It may be, as in the analogy that the collective case suggests, that reason is a pattern to be achieved among the elements that go to make the agent, not itself one of the elements involved. Discourse with others or with 
themselves will make clear to agents that this or that action is required of them if they are to count as coherent and conversable. But consistently with an agent as a whole recognising this - in parallel to how the group as a whole might recognise what it is required to do - there may be different voices within his or her make-up that continue to register dissent and continue to prove recalcitrant. We may often think of akrasia materialising as a result of precisely that sort of recalcitrance triumphing.

What might be the voices that go to constitute an individual agent, in the way in which different individuals constitute a group? One possibility would be to conceive of the voices required as the different modalities of cognition and motivation - the different perspectives - between which individuals often describe themselves as being undecided. There are longer-term and shorter-term perspectives, for example; altruistic and egocentric, or social and personal perspectives; perspectives that are relatively warm or involved and perspectives that are relatively cool or detached; and so on. We might think of these perspectives all being engaged in decision-making, with the engagement being regulated by the agent's sense of what reason overall requires. And we might think of akrasia appearing so far as some of the perspectives prove resistant to the adjustments that overall reason dictates and prove capable of affecting action.

There is no problem in seeing how the different voices in a person might give counsel that offends against reason, where we conceive of reason as a certain unified sort of pattern. As there are discursive dilemmas that arise for any group, so there will be dilemmas that arise among these voices, even if the voices are each them consistent in their own recommendations.

Imagine that a person confronts the issue of whether or not to buy a Volvo, where it is assumed that the decision turns on two questions: one, whether it would be good to have a car; and two, whether a Volvo is the best sort of car to have. And suppose that the relevant voices in a person are: $A$, the economic voice of self-interest; $B$, the ecological voice of the environment; and $C$, the voice concerned with what will impress the neighbours. It is entirely possible that these voices may give support on the following pattern, where support can be thought of as a sort of voting. 
Good to have a car? Is Volvo the best car? Buy a Volvo?

$\begin{array}{llll}\text { A. } & \text { Yes } & \text { No } & \text { No } \\ \text { B. } & \text { No } & \text { Yes } & \text { No } \\ \text { C. } & \text { Yes } & \text { Yes } & \text { Yes }\end{array}$

\section{Matrix III}

The pattern of support represented in the matrix is entirely intuitive. The economic self A recommends getting a car, because of the saving of time involved, but recommends against the relatively expensive Volvo. The ecological self $B$ votes against a car, for standard environmental reasons, but registers that a Volvo is the best sort of car, given its low emission levels. And the statusoriented self $\mathrm{C}$ recommends both in favour of getting a car and in favour of getting the praticularly impressive Volvo. But the result is that while there is a majority of voices that think it would be good to get a car, and a majority that think a Volvo is the best car, there is also a majority against getting a Volvo. We might imagine the person who operates under the influence of such voices coming to the view that he or she should buy a Volvo but proving akratic when it comes to phoning the dealer.

The picture of individual akrasia that this suggests is attractively egalitarian and emphasises, intuitively, that the recalcitrant elements in the akratic agent need not be voices of temptation but voices that make a serious claim on the person. It would enable us to avoid the downgrading of inclination and emotion that typifies more standard approaches, and allow us to enfranchise the affective as well as the intellectual voices within us. The most admirable human beings, according to the picture projected, would be those who let the voices of the heart as well as the voices of the head each have their say on every issue. They would be committed to achieving rational unity in themselves but not at the cost of suppressing any such voices. They would renounce the sort of ideal sometimes imagined in traditional moral theory: that of being someone in whom only one voice speaks, and in whom all elements have been drilled into march to the beat of one drum.

Our discussion of collective akrasia not only makes an egalitarian vision of akrasia available, it may also help to explain why the hierarchical picture 
remains so prominent. We saw in discussion of how collectives achieve selfcontrol that one way of doing so is by giving over control, in the event of any rational dissension, to certain considerations or to a certain individual or set of individuals. One way in which individuals may achieve self-control is by giving over control, in parallel fashion, to privileged sorts of considerations or to a privileged sort of voice. The most plausible version of this strategy would be to give control to more general, principled considerations or to give control to the cool voice that marshalls such considerations in our reasoning. And that is precisely the sort of strategy supported in traditional religious and moralistic writings.

So far as this strategy of self-control has been the most salient one around, it may have given life to the hierarchical conception of akrasia. For the strategy suggests that the essential problem in akrasia is the fact that more particularistic considerations push us away from the rule of the principled considerations that govern by right, or that the warmer voices of feeling and emotion rebel against the cool, detached voice that is properly placed in authority above them.

Akrasia is not exclusively action-centred in manifestation

According to the account given of collective akrasia, the malaise involved has a distinctively practical aspect (Pettit and Smith 1993). The agent fails to achieve rational unity despite operating within feasible limits and under favourable conditions. Specifically, the agent fails to achieve rational unity as a result of a divergence among its members on the question of what it ought to do and a failure on their part to come into line with the demands of reason on the group overall. But though the sort of failure involved has this practical aspect, it is a striking feature of the malaise described that it can affect, not just what the agent does or forms the intention of doing, but also what it judges to be the case and thereby comes to believe. Collective akrasia is not exclusively action-centred.

The reason this is so is that the difficulty that gives rise to akrasia - the difficulty made vivid in the discursive dilemma - can affect the formation of judgment as well as the formation and enactment of intention. In our original example of a discursive dilemma, the three members of a group give majority 
support to ' $\mathrm{p}$ ' and to 'if $\mathrm{p}$, then $\mathrm{q}$ ' but not to ' $\mathrm{q}$ '; under the rules described indeed, they effectively deny that q. Just as the failure of the group to intend or to act as certain commitments require can be explained by the recalcitrance of a relevant majority, so such recalcitrance may explain the failure of the group to form such a judgment. And if it does explain that sort of failure, then we have to see the group's not making that judgment as a manifestation of akrasia.

Nothing in this line of thought should be surprising. The making of a judgment that $\mathrm{s}$ - the acceptance of a corresponding formula - involves the formation of a belief that s, so far as the agent becomes disposed thereby to act as the judgment rationally requires: to act as if it were the case that $\mathrm{s}$. But the making of any judgment constitutes an action. The group acts in making a judgment on the question 's or not s?'; it decides to put the matter to a vote. And the group acts in actually forming the judgment that s; it goes through the process of voting. Akrasia can affect the group's performance in regard to those actions and so that it can affect its performance in regard to the formation or nonformation of an associated belief. Even if the group is required by its own lights to believe that $\mathrm{s}$, it is clearly going to be possible for it to fail to form any belief on the matter or to come to form the belief that not $s$; and this is clearly going to be possible, morever, in intuitively normal conditions of functioning.

The lesson is that akrasia is not exclusively action-centred in its manifestations. And that lesson, it transpires, may apply in the individual as well as in the collective case. Assume, uncontroversially, that one of the ways in which individuals form beliefs is by making judgments: by endorsing relevant formulae, taking them to be well-supported, and by becoming disposed as a result of that endorsement to act as if they were true. If an individual can be conceptualised as a forum where different voices speak, and where the achievement of agency and personhood requires their continuing orchestration, then akrasia may strike here in the same way as with the collectivity. Despite agreed evidence as to what reason requires the individual to judge on some issue, the voices within the person may fail, akratically, to get their act together.

There may be reason why the individual is required to make a judgment on some matter like 's or not s?', and yet he or she might fail to address or 
resolve it. Or there might be reason for someone to judge that $s$, and yet the person might fail to support that judgment or might even support the judgment that not s. All the evidence might suggest that a friend has been disloyal, for example, and yet the voices of affection and nostalgia might refuse to go along, leading the agent to report, akratically: 'I know it's a compelling conclusion; but I just can't believe it'.

While this line on the possibility of belief-related akrasia is controversial, it is not unprecedented and it is not implausible (Mele 1987; Mele 1995). It is supported, for example, by the fact that we hold people responsible for the things they believe in domains where we think they are capable of judgment (Pettit and Smith 1996; Scanlon 1998). How could we hold people responsible in this way unless we thought that their beliefs were subject to personal control and yet that sometimes they failed, akratically, to exercise that control?

Conclusion

The upshot of our discussion is tantalising. We have seen that groups, but only groups of a distinctively integrated kind, can manifest akrasia. And that observation has sponsored three fairly well-pointed lessons for the nature of akrasia in general. It argues that akrasia is not mechanical in character but supposes a capacity to recognise the demands of reasons and to regulate in the light of them. It supports an image of akrasia in which the the problem is not a failure of the higher elements in a hierarchy to subdue lower elements but a failure among more or less equally ranked elements - equally ranked voices to get their act together. And it suggests that akrasia is not exclusively actioncentred in its manfestations, being a malaise that can affect the formation of judgment as well as the performance of action. None of these claims will prove irresistible, of course, but they should each make a serious claim on our attention.

They should make a claim on our attention, I have suggested, not just in relation to collectives but also in relation to individuals. The image of the individual as an amalgam of different voices is only a metaphor, of course, and there is no suggestion that those voices have the autonomy of different persons 
or contribute to the views of an individual in the procedurally procrustean manner of voters. But the point it conveys is surely engaging: that there may be profit in thinking of the individual as a plurality of perspectives that interact in a continuing search for the unity of a single, reasoned vision. And if we do think of the individual in that way then akrasia will have to be seen in the individual as well as the collective case as a phenomenon that is non-mechanical and nonhierarchical in nature and that is not exclusively action-centred in its manifestations. ${ }^{3}$

Philip.Petti@@anu.edu.au

\section{References}

Austin, J. (1869). Lectures on jurisprudence, or the philosophy of positive law. London.

Bratman, M. (1999). Faces of Intention: Selected Essays on Intention and Agency. Cambridge, Cambridge University Press.

Brennan, G. (1999). Collective Irrationality and Belief. Canberra, Research School of Social Sciences, Australian National University.

Chapman, B. (1998). “Law, Incommensurability, and Conceptually Sequenced Argument." University of Pennsylvania Law Review 146: 1487-1582.

Dennett, D. (1987). The Intentional Stance. Cambridge, Mass., MIT Press.

Gilbert, M. (1989). On Social Facts. Princeton, N.J., Princeton University Press.

Hume, D. (1978). A Treatise of Human Nature. Oxford, Oxford University Press.

Jackson, F. (1984). “Weakness of Will." Mind 93: 1-18.

Kornhauser, L. A. (1992). “Modelling Collegial Courts. I. Path-Dependence." International Review of Law and Economics 12: 169-85.

Kornhauser, L. A. (1992). “Modelling Collegial Courts. II. Legal Doctrine.” Journal of Law, Economics and Organization 8: 441-70.

Kornhauser, L. A. and L. G. Sager (1986). “Unpacking the Court.” $\underline{\text { Yale Law }}$ Journal 82.

Kornhauser, L. A. and L. G. Sager (1993). "The One and the Many: Adjudication in Collegial Courts." California Law Review 81: 1-59.

Korsgaard, C. M. (1999). "Self-Constitution in the Ethics of Plato and Kant." The Journal of Ethics 3: 1-29. 
Lewis, D. (1969). Convention. Cambridge, Mass., Harvard University Press. List, C. and P. Pettit (2001). The Aggregation of Sets of Judgments: An Impossibility Result. Canberra, Australian National University.

McGeer, V. and P. Pettit (2001). "The Self-regulating Mind." Language and Communication.

Meijers, A. (1994). Speech Acts, Communication and Collective Intentionality: Beyond Searle's Individualism. Utrecht, de Jonge.

Mele, A. (1987). Irrationality. Oxford, Oxford University Press.

Mele, A. (1995). Autonomous Agents. Oxford, Oxford University Press.

Pettit, P. (1993). The Common Mind: An Essay on Psychology, Society and Politics, paperback edition 1996, New York, Oxford University Press.

Pettit, P. (1999). “A Theory of Normal and Ideal Conditions." Philosophical Studies 96: 21-44.

Pettit, P. (2000). Groups with Minds of their Own. Canberra, Australian National University.

Pettit, P. (2001). "Deliberative Democracy and the Discursive Dilemma." Philosophical Issues.

Pettit, P. and M. Smith (1993). “Practical Unreason." Mind 102: 53-80.

Pettit, P. and M. Smith (1996). “Freedom in Belief and Desire." \ournal of Philosophy 93: 429-49.

Quinton, A. (1975). "Social Objects." Proceedings of the Aristotelian Society 75.

Scanlon, T. M. (1998). What We Owe To Each Other. Cambridge, Mass, Harvard University Press.

Searle, J. (1995). The Construction of Social Reality. New York, Free Press.

Sunstein, C. (2000). The Law of Group Polarization. University of Chicago, Chicago.

Tuomela, R. (1995). The Importance of Us. Stanford, CA, Stanford University Press.

\footnotetext{
${ }^{1}$ There are a number of disputes that divide writers in this recent literature and they come up in particular with the analysis of group intention. One bears on the effect-of-intention question: whether it is necessary for collective intention that those who try to enact it are licensed - perhaps licensed on the basis of an
} 
implicit agreement - in rebuking those who fail to do their part in advancing or securing the intention. Another relates to the intended-content question: whether it is necessary that each of us in the group intend not just that I, this individual behave in a certain way - presumably this is necessary - but also that we, the group do so. And a third concerns the intending-subject question: whether in addition we, the group must form an intention to do something - at whatever locus this is to be formed - such that this may not reflect anything that I or you intend that we do. I do not intend here to try to adjudicate on any of these disputes, though the position adopted in the next section does have implications for how they should be resolved.

${ }^{2}$ Why suppose that the individuals consider the issues separately? Why suppose, for example, that they consider whether the group should endorse ' $q$ ', in abstraction from the question as to whether it has already endorsed ' $\mathrm{p}$ ' and 'if $\mathrm{p}$, then $\mathrm{q}^{\prime}$ ? The argument could be run without this supposition but two considerations make it a natural one to make. First, there will be no loss in having the individuals consider the issues separately, so far as they are capable of putting any resultant incoherence right. And second, it would seem to be better policy to let the incoherences emerge, and then to look at how they should be put right, rather than to have individuals privilege existing group commitments and avoid incoherences emerging in the first place; it may be the existing commitments that should rationally be revised and not the commitment most recently supported by individual voting.

${ }^{3}$ This paper was first presented at the Centre for Applied Philosophy and Public Ethics, Canberra in March 2001, and I benefitted greatly from the various comments I received on that occasion. 